\title{
Current status of in vitro and in vivo antifungal activities of posaconazole
}

\author{
He Sun, Xin Su, Yi Shi \\ Department of Respiratory Medicine, Nanjing Clinical College, Second Military Medical University (Nanjing \\ General Hospital of Nanjing Military Command), Nanjing 210002, Jiangsu Province, China
}

\section{ABSTRACT}

Posaconazole (POS) is a new triazole drug with broad-spectrum in vitro activity against most yeasts and molds such as Candida, Cryptococcus neoformans, Aspergillus, Fusarium and Zygomycetes, as well as certain species of dimorphic fungi and endemic fungi. In immunocompetent or immunocompromised animal models with invasive fungal infections, POS has demonstrated highly effective, broad-spectrum antifungal activities. In vitro and in vivo antifungal activities of POS were superior to those of other azoles against Candida glabrata, Candida krusei, Aspergillus terrus, Fusarium and Zygomycetes. In vivo susceptibility studies have shown promising efficacy of POS against life-threatening fungal infections in animal models with different immune status and infection sites.

Key words: animal model, antifungal activity, posaconazole, triazole antifungal

\section{INTRODUCTION}

Rapid progress has been made in recent 10 years in the development of antifungal drugs. One important progress of recently developed new drugs is posaconazole (POS) (Noxafil, POS), which has demonstrated potent in vitro activity against clinically common yeasts and filamentous fungi, less common fungi as well as some endemic fungi and reliable efficacy against infections induced by these fungi in various tissues and organs of animal models with different immune status. The present work has provided a systemic review of studies on the in vivo and in vitro susceptibility and antifungal activity of POS, in the hope of facilitating clinicians' better understanding of the antifungal spectrum and antibiotic activity of POS, as well as their management of clinical indications.

\section{IN VITRO SUSCEPTIBILITY AND ANTIFUNGAL ACTIVITY}

\section{Candida species}

The azole resistance of Candida species has attracted tremendous attentions clinically. The in vitro activity of POS against Candida species is 2- to 4-fold higher than that of itraconazole. ${ }^{[1]}$ A study involving 3932 isolates of Candida species demonstrated that among all azole drugs, POS had the highest in vitro activity, with $97-98 \%$ of the isolates found to be susceptible at $\mathrm{MIC}_{90}$ $\leq 1 \mathrm{mg} / \mathrm{L}$, of which Candida albicans was the most susceptible $\left(\mathrm{MIC}_{90}, 0.015-0.030 \mathrm{mg} / \mathrm{L}\right)$ while Candida glabrata was the least susceptible $\left(\mathrm{MIC}_{90}, 1-2 \mathrm{mg} / \mathrm{L}\right)$. POS at a concentration of $\leq 1 \mathrm{mg} / \mathrm{L}$ resulted in $80 \%$ and $44 \%$ inhibition of C. glabrata and Candidapelliculosa, respectively and the $\mathrm{MIC}_{90}$ of POS remained unchanged for C. albicans, Candida krusei, Candida guilliermondii and Candida norvegensis which are resistant to fluconazole. ${ }^{[2]}$ All 2000 isolates from the blood of candidemia patients were found susceptible to POS in vitro (MIC, 0.03-2 mg/L). MICs for different Candida are: $0.03-0.13 \mathrm{mg} / \mathrm{L}$ for C. albicans, Candida parapsilosis and Candida lusitaniae, 1-2 $\mathrm{mg} / \mathrm{L}$ for Candida glarata, $0.06-1.00 \mathrm{mg} / \mathrm{L}$ for Candida tropicalis, $0.25-0.50 \mathrm{mg} / \mathrm{L}$ for C. krusei and $0.03-0.06 \mathrm{mg} / \mathrm{L}$ for Candida dubliniensis. ${ }^{[3]}$

\section{Cryptococcus species}

No Cryptococcus has been found resistant to POS until now. A study of Yildiran et al..$^{[4]}$ examined the in vitro activities of various azole drugs against 213 isolates 
of Cryptococcus neoformans from the cerebrospinal fluid of 192 patients during 1990-1999 and revealed MIC of 2-8 $\mathrm{mg} / \mathrm{L}$ for fluconazole, $\leq 0.125 \mathrm{mg} / \mathrm{L}$ for voriconazole and $\leq 0.015-0.06 \mathrm{mg} / \mathrm{L}$ for POS. The MIC of POS was the lowest and did not increase significantly over the 10 -year period. Results from the susceptibility testing of 1811 clinical isolates of C. neoformans showed that POS $(\leq 1 \mathrm{mg} / \mathrm{L}$ ) could result in $99 \%$ inhibition of C. neoformans, including C. neoformans var Cryptococcus gattii, C. neoformans var. neoformans and strains with fluconazole resistance. The MIC of POS was even lower than those of amphotericin $\mathrm{B}$ and fluconazole. ${ }^{\left[{ }^{[}\right]}$

\section{Filamentous fungi}

POS is the most active azole drug against filamentous fungi, inhibiting over $95 \%$ of the isolates of filamentous fungi at concentrations of $\leq 1 \mathrm{mg} / \mathrm{L}$, while the inhibition rate for voriconazole was $90 \%$. In vitro susceptibility testing involving 1423 isolates of Aspergillus from more than 200 medical centers found that POS was 16 times more active than amphotericin B. ${ }^{[6]}$ POS at $0.03 \mathrm{mg} / \mathrm{L}$ was already able to cause inhibition of Aspergillus, however, the inhibitory effect varied among Aspergillus species. The in vitro activity of POS against Aspergillus fumigatus was greater than those of voriconazole and itraconazole and POS was also found active against $A$. fumigatus that was resistant to voriconazole, itraconazole and amphotericin B. Although POS exhibited excellent in vitro activity against Aspergillus terreus which was resistant to amphotericin B, Aspergillus niger was not susceptible to POS in vitro. The in vitro activity of POS against Zygomycetes has greatly enhanced our confidence of clinical medication. Study on the in vitro activity against 86 isolates of Zygomycetes demonstrated that POS was more active than itraconazole and voriconazole, with MIC of $128 \mathrm{mg} / \mathrm{L}$ for voriconazole, $32 \mathrm{mg} / \mathrm{L}$ for itraconazole and $4 \mathrm{mg} / \mathrm{L}$ for POS. The susceptibility to POS varied among different strains of Zygomycetes and the MIC was 0.25-8.00 mg/L against Rhizopus, $0.125-8 \mathrm{mg} / \mathrm{L}$ against Mucor, $0.03-0.25 \mathrm{mg} / \mathrm{L}$ against Absidia and $0.03-1.00 \mathrm{mg} / \mathrm{L}$ against Cunninghamella. ${ }^{[7]} \mathrm{A}$ study by Sun et al. ${ }^{[8]}$ showed that the MIC of POS against 37 isolates of Zygomycetes was $0.25-4 \mathrm{mg} / \mathrm{L}$, with lower in vitro activity than amphotericin $\mathrm{B}$ but higher activity than other azole drugs.

\section{Other rare fungi}

POS is active against most dimorphic fungi and endemic fungi. The $\mathrm{MIC}_{90}$ against dermatophyte is $1 \mathrm{mg} / \mathrm{L}$, slightly higher than that of itraconazole. ${ }^{[9]}$ POS is highly effective against Blastomyces dermatitidis, Histoplasma capsulatum (MIC $<0.01-2.00 \mathrm{mg} / \mathrm{L}$ for both) and Coccidioides immitis (MIC, $0.25-1.00 \mathrm{mg} / \mathrm{L}$ ) and less active against Sporothrix schenckii. It has also exhibited antibiotic activity against several black yeasts (Exophiala jeanselmei, Rhinocladiella). ${ }^{[10]}$ There are still controversies about the in vitro activity against $S$ cedosporium apiospermum. ${ }^{[7]}$ The comparison of in vitro activities among various azole drugs and amphotericin B was shown in Table 1. ${ }^{[11]}$

\section{IN VIVO EXPERIMENTS}

POS exhibits excellent tissue penetration and remarkable effects in the prevention and treatment against most fungal pathogens in animal models with different immune status and infection sites, which has provided adequate data for the clinical medication.

\section{Saccharomyces}

POS is highly active against Saccharomyces in vivo and highly effective in animal models of infection. POS had positive effects in the prevention and treatment of disseminated infection caused by inoculation with $C$. albicans which were susceptible, intermediate or resistant to fluconazole in immunocompetent and irradiated CF1 mice. The $50 \%$ protective doses (PD50S) were $1.5-19.4 \mathrm{mg} /(\mathrm{kg} \bullet \mathrm{d})$ for preventive medication and $0.04-15.6 \mathrm{mg} /(\mathrm{kg} \bullet \mathrm{d})$ for therapeutic medication. POS was superior to fluconazole in the prevention and treatment of disseminated infection induced by $C$. albicans that were intermediate and resistant to fluconazole in mice. Although POS was not detected in the cerebrospinal fluid of immunosuppressive rabbits, it was found equally active as fluconazole in the cerebrospinal fluid of rabbits with cryptococcal meningitis. For the treatment of disseminated cryptococcal infection in CD1 mice, POS $(3 \mathrm{mg} /(\mathrm{kg} \bullet \mathrm{d})$ and oral administration of $10 \mathrm{mg} /$ $(\mathrm{kg} \bullet \mathrm{d})$, for 10 successive days) extended the survival time of the mice and reduced the fungal load in the brain and lung tissues. Its efficacy was positively correlated with the dosage and was superior to that of amphotericin B $\left(0.3 \mathrm{mg} /(\mathrm{kg} \bullet \mathrm{d})\right.$ for intravenous injection). ${ }^{[12]}$ These in vivo studies further demonstrated the strong antifungal activity of POS against Saccharomyces.

\section{Filamentous fungi}

POS is highly active against $A$ spergillus and reliably potent in animal models. For immunosuppressive rabbits suffering from disseminated $A$. fumigatus infection, POS $(2.5 \mathrm{mg} /$ $(\mathrm{kg} \bullet \mathrm{d})$ and $10 \mathrm{mg} /(\mathrm{kg} \bullet \mathrm{d}))$ could improve the survival rate of rabbits and reduce the fungal load in the brain and lung tissues, with an equal efficacy to amphotericin B and superior efficacy to itraconazole. For immunosuppressive mice with $A$. fumigatus and Aspergillus flavus infection in their lungs, both preventive and therapeutic medication of POS remarkably improved the survival rate of the mice and reduced the fungal load in lung tissues, with respective PD50S of $3.6-29.9 \mathrm{mg} / \mathrm{kg}$ and $4.8-6.5 \mathrm{mg} /$ $\mathrm{kg}$ for therapeutic medication against $A$. fumigatus and A. flavus and a PD50S of $0.9-9.0 \mathrm{mg} / \mathrm{kg}$ for preventive medication, while a preventive effect of itraconazole 
Sun, et al.: In vitro and in vivo antifungal activities of posaconazole

\begin{tabular}{|c|c|c|c|c|c|}
\hline Fungi (strains) & POS & Itraconazole & Voriconazole & Fluconazole & Amphotericin B \\
\hline \multicolumn{6}{|l|}{ Candida } \\
\hline Candida albicans (3535) & 0.063 & 0.25 & 0.063 & 2.0 & 1.0 \\
\hline Candida glabrata (1218) & 2.0 & 4.0 & 2.0 & 64.0 & 1.0 \\
\hline Candida parapsilosis (970) & 0.25 & 0.5 & 0.125 & 4.0 & 1.0 \\
\hline Candida tropicalis (719) & 0.25 & 0.5 & 0.5 & 4.0 & 1.0 \\
\hline Candida krusei (189) & 1.0 & 1.0 & 0.5 & 64.0 & 1.0 \\
\hline Candida lusitaniae (84) & 0.25 & 2.0 & 0.06 & 34.0 & 2.0 \\
\hline \multicolumn{6}{|l|}{ Aspergillus } \\
\hline Aspergillus fumigatus (1119) & 0.5 & 1.0 & 0.5 & - & 1.0 \\
\hline Aspergillus niger (101) & 0.5 & 2.0 & 2.0 & - & 1.0 \\
\hline Aspergillus flavus (89) & 0.5 & 1.0 & 1.0 & - & 2.0 \\
\hline Aspergillus terreus (22) & 0.25 & 0.5 & 0.5 & - & 2.0 \\
\hline \multicolumn{6}{|l|}{ Zygomycetes } \\
\hline Rhizopus (32) & 8.0 & 32.0 & 128.0 & - & 2.0 \\
\hline Mucor (18) & 16.0 & 32.0 & 128.0 & - & 1.0 \\
\hline Absidia (16) & 0.25 & 0.5 & 128.0 & - & $0.125-2.0$ \\
\hline Cunninghamella (6) & $0.031-1.0$ & $0.125-2.0$ & $8.0-128.0$ & - & $0.125-2.0$ \\
\hline Apophysomyces (5) & $0.031-4.0$ & $0.031-8.0$ & $16.0-128.0$ & - & $0.031-4.0$ \\
\hline Phialophora (4) & $0.016-2.0$ & $0.016-0.125$ & $0.5-4.0$ & - & $0.063-0.5$ \\
\hline Rhizomucor (3) & $0.016-0.25$ & $0.016-0.25$ & 2.0-16 & - & $0.063-0.125$ \\
\hline Cokeromyces (2) & $0.25-4.0$ & $0.25-8.0$ & $16.0-64.0$ & - & $0.125-0.5$ \\
\hline \multicolumn{6}{|l|}{ Fusarium } \\
\hline Fusarium solani (39) & 32.0 & - & 32.0 & - & 32.0 \\
\hline Fusarium oxysporum (12) & 4.0 & - & 32.0 & - & 16.0 \\
\hline \multicolumn{6}{|l|}{ Other species } \\
\hline Cryptococcus (271) & 0.25 & 0.5 & 0.125 & 8.0 & 1.0 \\
\hline Actinomyces (80) & 32.0 & 64.0 & - & - & 32.0 \\
\hline Histoplasma capsulatum (53) & 0.25 & 0.063 & - & - & 0.5 \\
\hline Pseudallescheria (41) & 1.0 & 0 & - & - & 4.0 \\
\hline Scedosporium (26) & 1.0 & 32.0 & - & - & 8.0 \\
\hline Coccidioides (25) & 0.25 & 0.25 & - & - & 0.5 \\
\hline
\end{tabular}

POS: Posaconazole, MIC: Minimum inhibitory concentrations

could hardly been found on the pulmonary infection induced by these two strains (PD50S $>75 \mathrm{mg} / \mathrm{kg}$ ). POS $(10 \mathrm{mg} / \mathrm{kg}$ and $25 \mathrm{mg} / \mathrm{kg}$ ) could completely eliminate $60 \%$ of A. fumigatus but only $3 \%$ of A. flavus in mice lungs, suggesting a higher in vivo activity against $A$. fumigatus than that against $A$. flavus. For immunosuppressive rats with $A$. fumigatus in their lungs, the efficacy of POS (2-10 $\mathrm{mg} / \mathrm{kg}$ ) was dependent on its dosage and was similar to that of amphotericin B. However, $20 \mathrm{mg} / \mathrm{kg}$ POS was more potent than the maximum dosage of amphotericin $\mathrm{B}(4 \mathrm{mg} / \mathrm{kg}$ for intravenous injection) and eliminated pulmonary infection more effectively. ${ }^{[13]}$ For persistently neutropenic rabbits with $A$. fumigatus infection in lungs, the preventive medication of POS with a dosage range of $2-20 \mathrm{mg} /(\mathrm{kg} \bullet \mathrm{d})$ significantly extended the survival time of rabbits and reduced the fungal load in lungs, whereas the therapeutic medication almost completely eliminated the focus of infection in pulmonary and achieved a $72 \%$ survival rate of the rabbits. The efficacy of POS was superior to that of itraconazole and comparable to that of amphotericin B. ${ }^{[14]}$ For transient neutropenic mice with disseminated infection by itraconazole-resistant stains of A. fumigatus, the efficacy of POS $(5-25 \mathrm{mg}$ / $\mathrm{kg}$ for oral administration once a day) was positively correlated with its dosage. It could significantly extend the survival time of mice with infections and reduce the fungal load in lung and renal tissues. For persistently neutropenic rabbits and mice with disseminated $A$. terreus infection in lungs, POS could prolong the survival time of both infected animals and reduce the fungal load in lungs, while caspofungin only prolonged the survival time of mice and no indication of effect was found for amphotericin B $(1 \mathrm{mg} / \mathrm{kg})$ or liposomal amphotericin B $(1 \mathrm{mg} / \mathrm{kg}) \cdot{ }^{[15]}$ For neutropenic mice with disseminated Mucor infection, POS ( $\geq 15 \mathrm{mg} / \mathrm{kg}$, twice a day) could increase the survival rate of infected mice and reduce the fungal load in tissues, while the equivalent dosage of itraconazole (30 mg/kg, twice a day) had no effect. The efficacy of POS (30 mg/kg, twice a day) was comparable to that of amphotericin B. ${ }^{[16]}$ For mice with disseminated Rhizopus and Absidia corymbifera infection, POS behaved differently among various species, ineffective against Rhizopus oryzae, partially effective against Absidia corymbifera and effective against Rhizopus microsporus 
in a dose-dependent manner, while all strains were found susceptible to amphotericin B which significantly prolonged the survival time of the infected mice. ${ }^{[17]}$

\section{Other rare fungi}

POS was superior to the other azole drugs in the antibiotic activity against infections caused by rare fungi. For transient neutropenic mice with disseminated Pseudallescheria infection, POS could significantly reduce the fungal load in vivo, with overall efficacy superior to itraconazole and comparable efficacy to fluconazol in improving the survival rate of the infected mice. ${ }^{[18]}$ The therapeutic efficacy of POS in treating immunocompetent mice with disseminated Fusarium infection was positively correlated with the dosage and high-dosage of POS (50 mg/ $\mathrm{kg}$ and $100 \mathrm{mg} / \mathrm{kg}$ ) exhibited comparable efficacy to amphotericin B $(1 \mathrm{mg} / \mathrm{kg})$. For immunocompetent and athymic mice with disseminated dematiaceous fungal infection, the efficacy of POS was dependent on its dosage in both cases. It could significantly reduce the fungal load in tissues and increase the survival rate of the mice. ${ }^{[19]}$ For immunocompetent mice with pulmonary blastomycosis, POS $(25 \mathrm{mg} / \mathrm{kg})$ could achieve complete removal of fungi from lung tissues and significantly prolong the survival time of mice, with a comparable efficacy to the standard dosage of amphotericin B $(1 \mathrm{mg} / \mathrm{kg}$, intravenous injection) and markedly superior efficacy to itraconazole $(150 \mathrm{mg} / \mathrm{kg})$. For the treatment of immunosuppressive mice with disseminated coccidioidomycosis, POS also completely eliminated fungi in lung tissues, 200 times more effective than fluconazol $(100 \mathrm{mg} / \mathrm{kg})$ and 50 times more effective than itraconazole $(100 \mathrm{mg} / \mathrm{kg}) \cdot{ }^{[13]}$ For immunocompetent and $\mathrm{CD} 4^{+} / \mathrm{CD} 8^{+}$-deficient mice with disseminated histoplasmosis, POS was effective in both cases and POS treatment $(\geq 0.25 \mathrm{mg} / \mathrm{kg})$ could achieve $100 \%$ survival rate in the infected immunocompetent mice. However, for mice with disseminated infection due to pan-resistant $S$. apiospermum, no indication of effect was found by either POS alone or in combination with granulocyte colony-stimulating factor (G-CSF) $\cdot{ }^{[13]}$ Overall, the effect of POS on infections caused by rare fungi is superior to that of itraconazole and comparable to that of amphotericin B.

\section{IN VIVO AND IN VITRO STUDIES OF COMBINATION THERAPY}

Combination therapy is not the first choice for the initial treatment of invasive fungal infections, but it can improve the success rate of treating drug-resistant, refractory and mixed fungal infections. In vivo and in vitro drug susceptibility testing has provided solid evidence for clinical treatment. For example, according to an in vitro drug susceptibility testing of C. glabrata that was resistant or intermediate to azoles, the combination of POS and terbinafine showed synergistic effect against $12 \%$ of the isolates. ${ }^{[20]}$ The combination of POS and caspofungin was found to be synergistic against $18 \%$ of the 119 isolates (including 4\% fluconazol-resistant strains) of C. glabrata $^{[21]}$ For the treatment of mice with systemic Candida infections, POS and amphotericin $\mathrm{B}$ at four dose levels each were tested in all possible combinations and $65.3 \%$ of the combination therapies further prolonged the survival time of the mice, superior to the monotherapies $(P<0.05) \cdot{ }^{[22]}$ However, for the treatment of mice with systemic $C$. neoformans infection, the combination of amphotericin B and POS was not superior to amphotericin $\mathrm{B}$ alone in extending the survival time of mice and reducing the fungal load in vivo. ${ }^{[23]}$ POS in combination with 5-fluorocytosine exhibited higher in vitro activity against $C$. neoformans than using each drug alone and for the treatment of BALB/V mice with disseminated Cryptococcus infection and ICR mice with cryptococcal meningitis, POS $(2 \mathrm{mg} /(\mathrm{kg} \bullet \mathrm{d})$ and $20 \mathrm{mg} /(\mathrm{kg} \bullet \mathrm{d})$, oral administration for $10 \mathrm{~d})$ in combination with 5-fluorocytosine $(10-60 \mathrm{mg} /(\mathrm{kg} \bullet \mathrm{d})$, oral administration for $10 \mathrm{~d}$ ) could lead to a further reduction of the fungal load in brain tissues but not the extension of survival time of the mice. ${ }^{[12]}$ For the treatment of mice with disseminated $A$. fumigatus and $A$. flavus infections, POS (0.1-25 mg/kg) and caspofungin $(0.05-10 \mathrm{mg} / \mathrm{kg}$ ) at three dosage levels each were examined in all possible combinations and $74 \%$ of the combination therapies further prolonged the survival time of the mice, superior to the monotherapies. Moreover, there was no indication of resistance in any of the combination therapies. ${ }^{[16]}$ However, when the combination of POS with G-CSF was used for the treatment of immunosuppressive mice with disseminated Zygomycetes infection, the combination therapy was not found superior to POS alone. ${ }^{[24]}$ Intensive studies on the mechanisms of combination therapy remain to be conducted in standard animal models to facilitate more effective and reliable combination treatment.

\section{REFERENCES}

1. Galgiani JN, Lewis ML. In vitro studies of activities of the antifungal triazoles SCH56592 and itraconazole against Candida albicans, Cryptococcus neoformans, and other pathogenic yeasts. Antimicrob Agents Chemother 1997;41:180-3.

2. Pfaller MA, Messer SA, Boyken L, Hollis RJ, Rice C, Tendolkar S, et al. In vitro activities of voriconazole, posaconazole, and fluconazole against 4,169 clinical isolates of Candida spp. and Cryptococcus neoformans collected during 2001 and 2002 in the ARTEMIS global antifungal surveillance program. Diagn Microbiol Infect Dis 2004;48:201-5.

3. Ostrosky-Zeichner L, Rex JH, Pappas PG, Hamill RJ, Larsen RA, Horowitz HW, et al. Antifungal susceptibility survey of 2,000 bloodstream Candida isolates in the United States. Antimicrob Agents Chemother 2003;47:3149-54.

4. Yildiran ST, Fothergill AW, Sutton DA, Rinaldi MG. In vitro susceptibilities of cerebrospinal fluid isolates of Cryptococcus 
neoformans collected during a ten-year period against fluconazole, voriconazole and posaconazole (SCH56592). Mycoses 2002;45:378-83.

5. Pfaller MA, Messer SA, Boyken L, Rice C, Tendolkar S, Hollis RJ, et al. Global trends in the antifungal susceptibility of Cryptococcus neoformans (1990-2004). J Clin Microbiol 2005;43:2163-7.

6. Langner S, Staber PB, Neumeister P. Posaconazole in the management of refractory invasive fungal infections. Ther Clin Risk Manag 2008;4:747-58.

7. Torres HA, Hachem RY, Chemaly RF, Kontoyiannis DP, Raad II. Posaconazole: A broad-spectrum triazole antifungal. Lancet Infect Dis 2005;5:775-85.

8. Sun QN, Fothergill AW, McCarthy DI, Rinaldi MG, Graybill JR. In vitro activities of posaconazole, itraconazole, voriconazole, amphotericin $\mathrm{B}$, and fluconazole against 37 clinical isolates of zygomycetes. Antimicrob Agents Chemother 2002;46:1581-2.

9. Barchiesi F, Arzeni D, Camiletti V, Simonetti O, Cellini A, Offidani $\mathrm{AM}$, et al. In vitro activity of posaconazole against clinical isolates of dermatophytes. J Clin Microbiol 2001;39:4208-9.

10. Nucci M, Akiti T, Barreiros G, Silveira F, Revankar SG, Sutton DA, et al. Nosocomial fungemia due to Exophiala jeanselmei var. jeanselmei and a Rhinocladiella species: Newly described causes of bloodstream infection. J Clin Microbiol 2001;39:514-8.

11. Xia L, Liu L, Fu D. A novel broad-spectrum triazole antifungal, pasaconazozle. Chin J New Drugs 2007;16:1226-31.

12. Barchiesi F, Schimizzi AM, Najvar LK, Bocanegra R, Caselli F, Di Cesare S, et al. Interactions of posaconazole and flucytosine against Cryptococcus neoformans. Antimicrob Agents Chemother 2001;45:1355-9.

13. Groll AH, Walsh TJ. Antifungal efficacy and pharmacodynamics of posaconazole in experimental models of invasive fungal infections. Mycoses 2006;49:S7-16.

14. Petraitiene R, Petraitis V, Groll AH, Sein T, Piscitelli S, Candelario $\mathrm{M}$, et al. Antifungal activity and pharmacokinetics of posaconazole (SCH 56592) in treatment and prevention of experimental invasive pulmonary aspergillosis: Correlation with galactomannan antigenemia. Antimicrob Agents Chemother 2001:45:857-69.

15. Graybill JR, Hernandez S, Bocanegra R, Najvar LK. Antifungal therapy of murine Aspergillus terreus infection. Antimicrob Agents Chemother 2004;48:3715-9.

16. Sun QN, Najvar LK, Bocanegra R, Loebenberg D, Graybill JR. In vivo activity of posaconazole against $M u c o r$ spp. in an immunosuppressedmouse model. Antimicrob Agents Chemother 2002;46:2310-2.
17. Dannaoui E, Meis JF, Loebenberg D, Verweij PE. Activity of posaconazole in treatment of experimental disseminated zygomycosis. Antimicrob Agents Chemother 2003;47:3647-50.

18. GonzrtherbsdsTijerina R, Najvar LK, Bocanegra R, Rinaldi MG, Loebenberg D, et al. Activity of posaconazole against Pseudallescheria boydii: In vitro and in vivo assays. Antimicrob Agents Chemother 2003;47:1436-8.

19. Graybill JR, Najvar LK, Johnson E, Bocanegra R, Loebenberg D. Posaconazole therapy of disseminated phaeohyphomycosis in a murine model. Antimicrob Agents Chemother 2004:48:2288-91.

20. Perea S, Gonzalez G, Fothergill AW, Sutton DA, Rinaldi MG. In vitro activities of terbinafine in combination with fluconazole, itraconazole, voriconazole, and posaconazole against clinical isolates of Candida glabrata with decreased susceptibility to azoles. J Clin Microbiol 2002;40:1831-3.

21. Oliveira ER, Fothergill AW, Kirkpatrick WR, Coco BJ, Patterson TF, Redding SW. In vitro interaction of posaconazole and caspofungin against clinical isolates of Candida glabrata. Antimicrob Agents Chemother 2005;49:3544-5.

22. Cacciapuoti A, Gurnani M, Halpern J, Norris C, Patel R, Loebenberg D. Interaction between posaconazole and amphotericin $\mathrm{B}$ in concomitant treatment against Candida albicans in vivo. Antimicrob Agents Chemother 2005;49:638-42.

23. Barchiesi F, Spreghini E, Schimizzi AM, Maracci M, Giannini D, Carle $\mathrm{F}$, et al. Posaconazole and amphotericin B combination therapy against Cryptococcus neoformans infection. Antimicrob Agents Chemother 2004;48:3312-6.

24. Saoulidis S, Simitsopoulou M, Dalakiouridou M, Walsh TJ, Wheat LJ, Papaioannidou P, et al. Antifungal activity of posaconazole and granulocyte colony-stimulating factor in the treatment of disseminated zygomycosis (mucormycosis) in a neutropaenic murine model. Mycoses 2011;54:e486-92.

How to cite this article: Sun $\mathrm{H}$, Su X, Shi Y. Current status of in vitro and in vivo antifungal activities of posaconazole. J Transl Intern Med 2013; 1(1): 18-22.

Source of Support: Supported by the Young Scientists Fund of the National Natural Science Foundation of China (81000003), Conflict of Interest: None declared 